This item was submitted to Loughborough's Research Repository by the author.

Items in Figshare are protected by copyright, with all rights reserved, unless otherwise indicated.

\title{
Online mobilization in comparative perspective: Digital appeals and political engagement in Germany, Italy, and the United Kingdom
}

\section{PLEASE CITE THE PUBLISHED VERSION}

https://doi.org/10.1080/10584609.2016.1201558

\section{PUBLISHER}

(c) Taylor \& Francis

\section{VERSION}

AM (Accepted Manuscript)

\section{PUBLISHER STATEMENT}

This work is made available according to the conditions of the Creative Commons Attribution-NonCommercialNoDerivatives 4.0 International (CC BY-NC-ND 4.0) licence. Full details of this licence are available at: https://creativecommons.org/licenses/by-nc-nd/4.0/

\section{LICENCE}

CC BY-NC-ND 4.0

\section{REPOSITORY RECORD}

Vaccari, Cristian. 2016. "Online Mobilization in Comparative Perspective: Digital Appeals and Political Engagement in Germany, Italy, and the United Kingdom". Loughborough University. https://hdl.handle.net/2134/28252. 


\section{Online Mobilization in Comparative Perspective: Digital Appeals and Political Engagement in Germany, Italy, and the United Kingdom}

This study analyses the relationship between online voter mobilization and political engagement in Germany, Italy and the United Kingdom during the 2014 European election campaign. Internet surveys of samples representatives of these countries' populations with internet access show that respondents who received an invitation to vote for a party or candidate via email or social media engaged in a significantly higher number of political activities than those who did not. Moreover, these relationships were stronger among those who followed the campaign less attentively, as well as in countries where overall levels of engagement with the campaign were lower (Germany and the UK) than where they were higher (Italy). These findings indicate that online mobilization may contribute to closing gaps in political engagement at both individual and aggregate levels, and thus suggest that digital media may contribute to reviving democratic citizenship. 
Citizen participation is a crucial pillar of democratic governance but, as Verba, Schlozman, and Brady (1995) wrote, many people do not participate in politics because nobody asked them to. By making it easier to circulate political messages, digital media enable voter mobilization by both politicians and citizens, potentially expanding the ways in which people are asked to participate and the kinds of people who do the asking. Whereas offline mobilization has been shown to have substantial implications for political engagement, few studies have assessed the relationship between online mobilization and political engagement. Moreover, due to the lack of comparative research we do not know whether systemic factors moderate these patterns, and if so, how.

\section{Voter Mobilization and Political Engagement}

Research on political participation has established clear links between political mobilization and participation. Rosenstone and Hansen argued that "political participation arises from the interactions of citizens and political mobilizers" (1993: 36). Similarly, Verba, Schlozman and Brady (1995) demonstrated that recruitment networks rooted in local communities or political organizations stimulate participation. Although most mobilization efforts by parties, campaigns and citizens take place around elections to encourage voting, mobilization has broader implications for other forms of electoral and non-electoral participation (Huckfeldt \& Sprague, 1992; Karp \& Banducci, 2007; Rosenstone \& Hansen, 1993; Wielhouwer \& Lockerbie, 1994).

The increasing popularity of digital media for political information and discussion has led many researchers to ask whether their use may contribute to political engagement. Two meta-analyses, largely comprising U.S. studies, show that most research found both internet (Boulianne, 2009) and social media use (Boulianne, 2015) to be positively associated with engagement, although experimental and panel studies are rare and doubts remain over the 
causal nature of such associations. Research has also found that individuals combine political activities occurring on the web with those in physical settings rather than keeping them separate (Oser at al. 2013). Accordingly, Gibson and Cantijoch (2013) showed that activities such as contacting politicians and signing petitions tend to be performed both online and offline, suggesting that political action is integrated across the web and in physical settings, while online and offline practices are more differentiated when it comes to seeking political news. Moreover, Cantijoch et al. (2015) found that lower-intensity online political activities, such as seeking information on the internet, spill over to subsequent levels of engagement in political discussion online, and Gil de Zúñiga, Molyneux, and Zheng (2014) found positive relationships between political self-expression on social media and political participation. Taken together, these studies suggest that there is a strong relationship between online and offline political action and that accessing and exchanging political information on social media may be conducive to political engagement both on the web and in physical spaces.

Compared with the robust tradition of research on offline mobilization and political engagement and the flourishing of studies on digital media and political engagement, research on digital mobilization and engagement has been rare. This gap needs addressing not only in light of the increasing popularity of online political communication, but also because digital mobilization presents some theoretically relevant characteristics that may have important implications for engagement. In particular, compared with face-to-face mobilization, digital mobilization appears to be less differentiated between elite- and citizen-initiated efforts and, partly as a result, more inclusive in its targets.

Rosenstone and Hansen (1993) distinguish between direct mobilization, purposefully orchestrated by political actors, and indirect mobilization, which occurs in citizens' social networks. Whereas the boundaries between direct and indirect mobilization are clear in faceto-face environments, they may be blurrier on digital platforms, where users can recirculate 
content originally published by political actors in ways that range from simple reproduction (by forwarding, sharing, or copying and pasting those messages) to creative appropriation and personalization (by adding one's thoughts, editing the original message, or repackaging hybrid messages that combine official and personal content).

Digital mobilization may also have broader scope than face-to-face mobilization. Because offline mobilization is costly, politicians predominantly use it to target citizens who are more likely to participate (Rosenstone and Hansen 1993). The rationality of this strategy and its negative implications are confirmed by Enos, Fowler and Vavreck (2014), who found that get-out-the-vote experiments disproportionally stimulate turnout among citizens who are more likely to vote. Relatedly, Hassell and Monson (2014) found that campaigns tend to send fundraising mail to previous donors rather than trying to activate new ones. However, when it comes to digital mobilization, Krueger (2006) found that email reaches a more inclusive audience than offline channels such as direct mail, telephone calls, and door-to-door canvassing. Because the marginal costs of email communication are practically null, political organizations can afford to send messages to any citizen on their list rather than choosing whom to mobilize based on their political predispositions.

Whereas studies of offline mobilization have addressed its relationship with both turnout and other modes of political engagement, most research on online mobilization has only focused on turnout, generally relying on randomized field experiments with treatments delivered via email and social media in the United States. Green and Gerber (2004) found that emails appealing to vote have negligible effects on both voter registration and turnout (see also Nickerson, 2007). By contrast, Malhotra, Michelson, and Valenzuela (2012) found that emails by official sources have a small but significant positive effect on turnout, while those coming from voter mobilization organizations have no effect. Bond and colleagues (2012) 
found that being exposed to a Facebook post claiming that a friend had voted had a small but significant effect on turnout.

However, the relationship between online mobilization and political engagement writ large has rarely been investigated. The only notable exception is Aldrich and colleagues' (2016) comparative analysis of the UK 2010 and US 2012 elections. Based on cross-sectional survey data, the authors found that online direct mobilization increased campaign participation in both countries. Moreover, indirect mobilization (measured without differentiating between online and offline modes) enhanced participation in the UK, while in the US online indirect mobilization increased engagement among younger voters. This research thus suggests a strong connection between online mobilization and engagement. However, the study covers two countries that the authors characterize as similar for their purposes, and does not address the implications of systemic differences between them. Interestingly, however, the authors find that US parties contact more voters online than UK parties, consistently with comparative research documenting the greater online professionalism of US political actors (Vaccari, 2013). They also observe that mobilization has greater potential to be effective where overall levels of participation are lower, as the ceiling for its effects is higher (Aldrich et al., 2016: 167).

To summarize, face-to-face mobilization is an important predictor of both turnout and other forms of participation, and some forms of digital mobilization can also stimulate turnout. However, we do not yet know whether digital mobilization can also contribute to citizens' broader repertoires of political engagement besides voting. We also do not know whether online mobilization has differential implications for participation among citizens with high and low levels of political involvement. Whereas offline mobilization may exacerbate participatory gaps due to politicians' strategic targeting of resources, the potential inclusiveness of online mobilization may reduce them, or leave them untouched. Finally, 
because little comparative research has been conducted on this topic, we do not know whether the context in which digital mobilization occurs affects its relationship with engagement. To begin addressing these gaps, I build on existing theory and evidence to formulate four hypotheses on the relationship between digital mobilization and political engagement in comparative perspective.

\section{Hypotheses}

Because offline mobilization has been found to be positively related with political engagement, and because online mobilization has the potential to be even broader in scope and more inclusive in its targets than offline mobilization, I expect that digital mobilization is positively correlated with political engagement (H1), even after controlling for other relevant antecedents. Moreover, I investigate whether and how attentiveness to the campaign moderates the relationship between online mobilization and engagement. For less attentive voters, who tend not to accumulate large amounts of political information, the socially cued information provided by online mobilization may provide a greater marginal incentive to become engaged than for more attentive voters, who may already have accumulated larger stocks of political information. I therefore hypothesize that attentiveness to the campaign moderates the relationship between digital mobilization and political engagement, and the relationship is negative ( $\mathrm{H} 2)$.

My remaining two hypotheses build on Aldrich et al.'s (2016) argument that mobilization has greater potential to increase engagement where and when citizens are not already highly engaged. I thus specify $\mathrm{H} 1$ by hypothesizing that the positive relationship between online mobilization and political engagement is stronger where overall levels of engagement are lower (H3). By the same logic, where overall engagement is lower mobilization should play a stronger role in closing the gap between those who pay more and 
less attention to the campaign. Therefore, I specify $\mathrm{H} 2$ by hypothesizing that attentiveness to the campaign moderates the relationship between digital mobilization and political engagement, the relationship is negative, and it is stronger where overall levels of engagement are lower (H4).

\section{Case Selection}

Testing $\mathrm{H} 3$ and $\mathrm{H} 4$ requires observable variation in the levels of overall citizen engagement with the election, which is where the comparative design of this research becomes relevant. The three countries included in this study—Germany, Italy, and the United Kingdom—differ under many respects, such as their party systems, media systems, and levels of technological diffusion. However, within the theoretical framework of this particular study, the comparison of Germany, Italy, and the United Kingdom in the context of the 2014 European elections must be understood as a device allowing to control for different levels of overall engagement with the campaign, as will be shown below. Moreover, the fact that the data were collected after a transnational election that occurred simultaneously across the three countries allows to keep constant the timing of the vote, the electoral system (proportional, with small variations), and the purpose of the vote (the election of Members of the European Parliament).

Although politicians, citizens, and the media generally consider European elections as less relevant than general election, the extent to which this is the case depends on countryspecific systemic and contextual factors. Since the first European elections in 1979, voter turnout-a useful proxy for participation-averaged 73.3\% in Italy, 53\% in Germany, and $33.8 \%$ in the UK. In the last three elections-in 2004, 2009 and 2014-average turnout was $64.7 \%$ in Italy, $44.8 \%$ in Germany, and $36.3 \%$ in the UK. These figures suggest that the Italian population tends to be more engaged with European elections than the German and British ones. Moreover, in 2014 various contextual factors raised the stakes in Italy while keeping 
them low in Germany and the UK. Just three months before the European vote, Matteo Renzi, the new and energetic leader of the centre-left Democratic Party, replaced fellow party member Enrico Letta as Italy's Prime Minister. Renzi had not even been a candidate during the 2013 general elections, and thus lacked a popular mandate. He bet that a strong showing of his party in the European elections would provide such legitimacy, and thus took a highprofile role in the campaign, presenting it as a clash between "hope and fear" and linking the fortunes of his government to the outcome. The main opposition party, the Five Star Movement, accepted Renzi's raising of the stakes and ran a very aggressive campaign centred on the claim that it would top the poll and use that success to oust the Prime Minister, who in their view had seized power illegitimately. Thus, the two main Italian parties ran high-profile campaigns claiming that the European vote was about much more than electing a few dozens of representatives. The political climate was much less heated in Germany-where the main centre-right and centre-left parties had joined a grand coalition after the 2013 general election and were in no mood to challenge each other too harshly—and the United Kingdom-where the two major parties kept a low profile to minimize the post-electoral fallout from the likely success of Eurosceptic UK Independence Party, which indeed ended up topping the poll. In sum, both systemic and contextual differences indicate that comparing Germany, Italy and the UK offers theoretically fruitful variation with respect to overall levels of engagement with the 2014 European election campaign, and thus allows operationalizing a central concept in my hypotheses.

Although certainly not as prominent as general elections, European elections are far from irrelevant. For one, voter turnout is on par with other prominent Western democracies. In 2014 the country with the lowest turnout among those studied here was once again the UK with $35.6 \%$, but this percentage was essentially identical to the $36 \%$ recorded in the United States midterm elections in the same year. Conversely, the country with the highest turnout in 
2014 among those studied here was Italy, and at 57.2\% its electoral participation is barely distinguishable from the 58\% observed in the U.S. 2012 Presidential elections. Moreover, as discussed above, second-order elections often acquire political significance either as popularity tests for the incumbent government, as noted for Renzi in Italy, or as catalysts for the ascendance of insurgent parties, as was the case with the UK Independence Party. After becoming the first party other than Labour or Conservatives to ever top the poll in a British European election, UKIP was granted major party status by the UK media regulator. This, in turn, had important consequences for the 2015 general election campaign, as it increased the amount of free airtime that the law obliged television networks to grant to UKIP and ensured that its leader would be invited for the first time in history to at least one of the televised leaders' debates.

\section{Data}

As discussed above, much useful research on the effects of mobilization is based on experiments, which are better suited to establishing causality than observational analyses. However, experimental studies generally focus on voter turnout as dependent variable, neglecting broader modes of political engagement such as the ones addressed here. This is why both classic (e.g. Verba, Schlozman, and Brady, 1995) and recent (e.g. Aldrich et al, 2016) research on the relationship between mobilization and engagement has employed surveys, as does the present study. Although surveys can make weaker claims to internal validity than experiments, they can be effective in achieving external validity, especially when comparing more countries at the same time-a task which would be logistically much more challenging, although not impossible, when employing an experimental design. That being said, this study does not aim to make strong causal claims on the correlations that it investigates, but hopes to highlight patterns hitherto neglected by both observational and experimental inquiries. 
This research focuses on mobilization that takes place online, hence its population of interest comprises all voters who, having access to the internet, can be mobilized in such a way. Accordingly, I rely on internet surveys based on samples constructed to be representative of the population with internet access based on key demographic characteristics. Because the population of interest is internet users rather than the general population, coverage bias is minimized. Although internet surveys based on panel samples suffer from several known biases (e.g. Baker et al. 2010), studies comparing in-person and internet surveys (Sanders et al. 2006), as well as probability and nonprobability samples (Pasek 2015) suggest that online panel-based samples tend to produce accurate estimates of relationships between politically relevant variables, even though they may not provide accurate point estimates of individual variables.

The surveys were fielded by IPSOS between May 27-June 20, 2014, immediately after the European Elections of 22-25 May. For each country, a sample of 1,750 respondents was constructed via online panels with non-monetary incentives. Invitations were sent until the sample achieved the target size and was representative of each country's population with internet access for gender, age, education, region of residence, and occupational condition. Response rates based on AAPOR's RR1 standard (2011) were 17\% for Germany, 21.4\% for Italy, and $20.1 \%$ for the UK. Because census-based sampling achieved a very close fit between sample margins and population margins, no weighting was required for the German and Italian samples. However, the percentage of unemployed respondents in the British sample was higher than in national figures, and as a result the British data were weighted to ensure that sample margins matched population margins on occupational condition too.

\section{Addressing Limitations in the Data}


Any type of observational data, such as those employed in this study, suffers from identification problems that need to be discussed. Individuals who remember being mobilized online when completing a survey may differ systematically from those who do not remember being mobilized with respect to relevant political attitudes and behaviours. Moreover, due to the strategic conduct of political actors discussed above, those same characteristics may be associated with the probability that individuals are mobilized (selection bias). These two patterns may also compound each other, as respondents who were prompted to act as a result of being mobilized may be more likely to remember being mobilized. As a result, regardless of whether digital mobilization enhances political engagement, political engagement may also increase the likelihood of (remembering) being mobilized online, as political actors and activists tend to mobilize citizens likely to participate in politics (reciprocal causation).

Although only experimental designs—and to a lesser degree panel surveys—could fully assuage these concerns, five factors should mitigate them in the context of this study. These involve theoretical considerations, the specific hypotheses tested in this study, the fact that the survey was administered online, the control variables included in the models, and the procedure with which the data were pre-processed. Although none of these arguments in and of itself may nullify selection bias and reciprocal causation, taken together they suggest that such issues should not be seen as fundamentally questioning the validity of the claims made here.

First, on theoretical grounds, I have argued above that online mobilization is cheaper and less differentiated between direct (elite-led) and indirect (citizen-led) modes than offline mobilization, and as a result it tends to reach broader targets (Krueger 2006). Online mobilization should be driven less by the choices of strategic political actors targeting citizens already likely to participate than by individuals' desire to engage their online contacts without any specific targeting strategy or capacity. Studying predominantly informal, cheap, and 
bottom-up mobilization should thus be less prone to reciprocal causation than studying costlier top-down efforts by strategic political actors, who tend to mobilize subjects who are comparatively more likely to be engaged and to recall being mobilized. A further theoretical issue that should be taken into consideration is that the original intent of the mobilization messages studied here, as will be shown in the next section, is to get recipients to simply vote for one party or candidate, not to engage in any form of broader political activism. Even assuming that the intentions of the senders may affect the characteristics of the recipients of online mobilization, the case for selection bias would be stronger if the dependent variable was vote choice or voter turnout-behaviours that the messages studied here did attempt to influence-than when the outcomes of interest-i.e., broader patterns of political engagement-differ from the specific actions that recipients were directly asked to perform, and on which basis they were presumably targeted by the authors of mobilization messages.

Secondly, if respondents who remembered being mobilized online differed systematically from those who did not remember that, attentiveness to the campaign should be one of the factors behind these differences. We should expect respondents who paid more attention to the campaign, all else being equal, to be more likely to recall both being mobilized and participating in political activities. As a result, the strength of the correlation between mobilization and engagement should increase as attention increases. However, this is exactly the opposite of what $\mathrm{H} 2$ argues, i.e., that the strength of this relationship should decrease as attention increases. Similarly, selection bias should be stronger in contexts where overall levels of engagement with the campaign are comparatively higher. The higher the stakes in the election, the more we should expect respondents to remember being mobilized and taking part in political activities. If that were the case, the relationship between mobilization and engagement should be stronger where overall engagement was higher. This runs counter to $\mathrm{H} 3$ and H4, which predict that such relationship should be weaker where overall engagement 
was higher. In sum, even if selection bias inflated estimates of the relationship between mobilization and engagement, it would actually make it more difficult to find support for three of the four hypotheses tested here.

Thirdly, social desirability and acquiescence to the interviewer may be among the factors causing some systematically biased over-reporting of both mobilization and engagement. However, self-administered online surveys such as the ones employed for this study suffer less from these biases than face-to-face and telephone surveys (Heerwegh, 2009; Kreuter, Presser, \& Tourangeau, 2008). Moreover, studies of the relationship between social media use and political engagement that employed panel samples have been substantially less likely to find positive and significant coefficients than those based on general population samples (Boulianne, 2015: 533)—which again should make it more difficult to reject the null hypotheses addressed in this research.

Fourthly, with respect to modelling, Vavreck (2007) has shown that controlling for covariates such as political efficacy, partisan strength, interest in politics, campaign attentiveness, and civic duty severs the correlation between errors in reported exposure to political stimuli and reported engagement in political activities. Accordingly, the models that will be presented below control for interest in politics, campaign attentiveness, political efficacy, ideology, and trust in parties. (Unfortunately, no measure of civic duty was available.)

Finally, to ensure that selection biases were addressed as fully as possible in statistical terms, I pre-processed the data using Propensity Score Matching (PSM), which takes into account the fact that respondents who recalled being mobilized online may systematically differ from those who did not before conducting any analysis estimating correlations between mobilization and engagement. This procedure ensures that any difference that will be found in political engagement between respondents who were and were not mobilized online is not 
related to the variables included in the models that make respondents more likely to remember being mobilized.

Following Klofstad et al. (2013), I applied PSM in four steps. First, I estimated the probability that respondents were mobilized online with a logistic regression featuring independent variables that can be expected to predict the probability that respondents recalled being mobilized online. The variables ${ }^{1}$ included in the model are: gender, age, education, income, frequency of social media use, political information obtained via social media, websites, newspapers, radio, and television, political efficacy, trust in political parties, interest in politics, attention to the 2014 campaign, left-right self-placement, country of respondent, having visited party or candidate websites, and intensity of political discussion on social media. ${ }^{2}$ Secondly, based on the regression results, I estimated a score for each respondent's propensity to report being mobilized online. Thirdly, I used these scores to match respondents so that at least one subject who had been mobilized online was matched to at least one subject who had not been mobilized, allowing multiple matching to maximize the number of respondents included in the analysis. The resulting dataset comprises 1,598 treated (mobilized) and 1,437 untreated (not mobilized) subjects, which constitute the sample for subsequent analyses. Finally, I used the propensity scores to calculate weights for the matched respondents, ${ }^{3}$ thus ensuring that the models employed to test my hypotheses are more affected by untreated subjects (i.e., not mobilized online) who are similar to treated subjects (i.e., mobilized online), and less by untreated subjects who are not similar to treated

\footnotetext{
${ }^{1}$ Because some variables had a relevant number of missing values, I imputed missing data for trust in parties, political efficacy, interest in politics, income, and frequency of political information via social media, websites, newspapers, radio, and television. The values were imputed on the basis of a model that also included gender, age, education, occupational condition, country, and ideology.

${ }^{2}$ The Nagelkerke's R-square coefficient for the regression was 0.373 .

${ }^{3}$ The weighting formula was as follows: mobilized+(1-mobilized)/(1-propensity), where "mobilized" is the dichotomous variable measuring whether respondents recalled being mobilized and "propensity" is their probability of being mobilized as estimated by the model. This formula ensures that respondents who recalled being mobilized were weighted as 1 , whereas those who did not recall being mobilized were weighted in inverse proportion to their estimated similarity to mobilized subjects. 
subjects. This should increase our confidence that the variables included in the models should not confound the relationship between online mobilization and political engagement.

\section{Variables}

The dependent variable measures respondents' political engagement as the number of activities that individuals recalled performing in the previous year among six different possibilities. These were chosen among a wider range of items included in the survey to cover a broad spectrum of activities: trying to convince someone to vote for a party, leader, or candidate; participating in the activities of a political party; taking part in public meetings and rallies on the elections; signing a petition or a referendum; contacting a politician to support a cause; and discussing national politics on social media. Consistently with research showing that online and offline action are increasingly intertwined (Oser et al. 2013), the questions did not specify where these activities had been performed (with the exception of discussing politics on social media), so the responses capture a variety of behaviours that take place both on the web and in physical settings. The Cronbach's $\alpha$ reliability score across the six items is 0.668. Table 1 shows the distribution of the variables in the three countries, as well as the wording of the questions employed to measure them. The index constituting the dependent variable was calculated by adding the number of "yes" answers that each respondent provided (treating "don't know" answers as missing values), and thus ranges from 0-6. Across all three countries, the mean was 2.08 and the standard deviation was 1.67 .

\section{Table 1 about here}

Online mobilization is the key independent variable of this study and was conceptualized taking into account Nielsen's (2011) classification of different campaigning tools according to their complexity and diffusion. Nielsen (2011) classifies email as a "mundane" tool and social media as "emerging" tools. In order to incorporate both types of tools, I employed two 
different questions that appeared in separate batteries and referred to appeals received via email and social media. Respondents were asked: "Various political activities are carried out via the Internet. During the past 12 months have you received email intended to convince you to vote for a specific candidate, leader or party?" and "Various political activities are carried out on social networks / social media platforms such as Facebook, Twitter, YouTube, etc. During the past 12 months have you received messages intended to convince you to vote for a specific candidate or party?". In both cases, respondents could answer "yes", "no", or "don't remember". I combined these variables by classifying respondents who answered "yes" to at least one question as having been mobilized and those who answered "no" to both questions as not having been mobilized. I excluded from the analysis respondents who answered “don't know" to both questions and those who answered "no" to one question and "don't know" to the other. The variable is thus dichotomous; in the PSM-weighted sample, $30.8 \%$ of respondents were classified as having been mobilized online.

The questions measuring online mobilization do not discriminate between direct (party-activated) and indirect (citizen-initiated) mobilization, as respondents were not asked to recall the source of the messages they may have received. As Aldrich et al. (2016) showed, direct and indirect mobilization can have different implications for political engagement. Importantly, however, they found direct online mobilization to be very rare in the UK (reaching only $2 \%$ of respondents), in contrast with the US where it was much higher; by contrast, indirect online mobilization was common in both countries. Since European parties are generally less keen than their American counterparts to employ digital media for campaigning (Vaccari, 2013), and since political actors strategically target mobilization efforts based on the importance of the outcome, it is conceivable that party-initiated direct online mobilization in the 2014 elections may not have been particularly high, and thus that most 
respondents who recalled being mobilized received messages from other citizens rather than politicians.

Because second-order elections tend to be more favourable competitive contexts for minor parties than general elections, it is conceivable that mobilization, engagement and attentiveness may be more concentrated among minor than major party supporters, which may confound the relationships between the main variables of interest to this research. However, when we divide respondents on the basis of whether they voted for a major ${ }^{4}$ or a minor party, minor party supporters were only slightly more likely to recall being mobilized online (32.5\% vs 29\%) and their levels of political engagement were actually lower than those of major party supporters ( 1.92 vs 2.27 on a 0-6 scale), as were their levels of attentiveness to the campaign ( 0.69 vs 0.77 on a $0-1$ scale). Therefore, the data do no suggest any substantial and consistent bias related to differential levels of mobilization and/or engagement among supporters of major and minor parties.

I test my hypotheses through multivariate Poisson regressions, which are appropriate when the dependent variable is a count variable. ${ }^{5}$ For both dependent variables, I ran four separate regressions, adding different interaction terms at each step. In model 1, which does not include interactions, the coefficient for online mobilization allows testing H1; in model 2, an interaction term between mobilization and attention to the campaign allows testing $\mathrm{H} 2{ }^{6}$ in model 3, an interaction term between mobilization and country of respondent (treating Italy as reference category) allows testing H3; finally, in model 4, interaction terms between

\footnotetext{
4 The following parties were considered as major: Christian Democratic Union and Social Democratic Party (Germany); Democratic Party, Five Star Movement, and Go Italy (Italy); Conservative Party, Labour Party (UK). 5 The coefficients in the bottom rows of Table 2 indicate that the data are not overdispersed and that the regressions fit them well. Across all models, the ratio between the Chi square and number of degrees of freedom is always lower than 1 , which indicates that the models actually overestimate the standard errors (which incidentally were calculated using formulas for robust estimators).

${ }^{6}$ Attention to the campaign was measured by the following question: "How closely did you follow the electoral campaign for the European elections in May 2014? Not at all closely; Not very closely; Fairly closely; Very closely; Don't know." "Don't know" answers were coded as missing data. In the PSM-weighted sample, the modal category was "fairly closely" (41.2\% of valid responses). 
mobilization, attention and country allow testing H4. The models also control for gender, age, education, income, frequency of social media use, exposure to political news on different media channels (television, newspapers, radio, social media, and websites), left-right selfplacement, political efficacy, ${ }^{7}$ trust in parties, interest in politics, country of the respondent (with Italy as reference category), having visited the official website of a party, leader or candidate in the previous year, and the proportion, among all social media posts published and read in the previous two months, of messages dealing with politics. All non-dichotomous variables have been normalized to range between 0 and 1 to facilitate comparisons across coefficients. ${ }^{8}$ Results are shown in Table 2

\section{Findings}

Model 1 tests $\mathrm{H} 1$ by assessing whether online mobilization is positively correlated with political engagement. The coefficient for online mobilization is positive and statistically significant, and this remains the case across all models even after several interaction terms have been added. The consistently positive and significant correlations between digital mobilization and political engagement support $\mathrm{H} 1$.

\section{Table 2 about here}

Testing $\mathrm{H} 2$ requires estimating whether and how attentiveness to the campaign moderates the relationship between mobilization and engagement. Hence, Model 2 adds an interaction term between mobilization and attentiveness, which captures how the relationship between mobilization and engagement changes at different levels of attention to the campaign. The

\footnotetext{
7 This variable combines answers to three questions measuring agreement or disagreement with the following statements: "People like me have no influence on what the government does"; "Politicians are interested in what people like me think"; "Sometimes politics is so complicated that you cannot understand what is happening". 8 One question employed to construct the index of political engagement and one of the two questions measuring online mobilization were only asked to respondents who reported having a profile on at least one major social networking site $(82.1 \%$ of German, $88 \%$ of Italians, and $85.9 \%$ of British respondents). Hence, findings should only be generalized to social media users in these countries. 
coefficient for this interaction term is negative and significant. Together with the fact that the coefficients for both mobilization and attention are positive and significant, this means that online mobilization is positively related with engagement among both more and less attentive respondents, but this positive relationship is stronger among those who paid less attention than among those who paid more attention. To clarify the implications of this finding, the left pane of Figure 1 plots the estimated values of the index of political engagement (with error bars reporting 95\% confidence intervals) among respondents who were mobilized online (the darker bars) and those who were not mobilized online (the lighter bars) at different levels of campaign attentiveness, setting all other variables to their mean. The figure shows that, among those who paid more attention than average (one standard deviation above the mean), the predicted index of political engagement is 2.4 for those who were mobilized versus 1.9 for those who were not mobilized, and the error bars indicate that the difference is statistically significant. However, if we look at respondents who paid less attention than average (one standard deviation below the mean), the gap between those who were mobilized online and those who were not is substantially higher as well as significant: 2.1 versus 1.3 . In sum, the strength of the relationship between mobilization and engagement decreases as attention to the campaign increases, as predicted by $\mathrm{H} 2$.

\section{Figure 1 about here}

Importantly, all models also include dummy variables that cluster respondents on the basis of their country, with Italy as reference category. The coefficients for both Germany and the UK are negative and significant across all four models, indicating that overall levels of engagement were substantially lower in these countries than in Italy once all the variables included in the models are accounted for. (Running the same models with the UK as reference category showed that the difference between British and German respondents is not statistically significant.) We can see this finding as a confirmation that some systemic and 
contextual characteristics of Germany and the UK substantially differentiate these countries from Italy in terms of political engagement, even after all the individual-level variables included in the models were taken into account. In turn, this means that comparing these countries effectively allows assessing the implications of different levels of systemic political engagement, which is required to test $\mathrm{H} 3$ and $\mathrm{H} 4$, and validates the case selection strategy described above.

In particular, $\mathrm{H} 3$ claims that the relationship between mobilization and engagement is stronger where overall levels of engagement are lower-in our case, in Britain and Germany compared to Italy. To test this hypothesis, Model 3 introduces interaction terms between mobilization and country, with Italy as reference category. With this set-up, the coefficient for mobilization captures the relationship between mobilization and engagement among Italian respondents only, whereas the coefficients for the interaction between mobilization and Germany/UK capture the additional effects of mobilization among respondents in those countries, in addition to those captured by the variable without interactions. As can be seen in Table 2, all three mobilization coefficients in Model 3 are positive and significant, which means that the relationship between mobilization and engagement, which is positive in all three countries, is relatively stronger in Britain and Germany-where levels of offline engagement were lower and thus mobilization faced a higher ceiling-than in Italy-where engagement was higher and efforts to increase it met a lower ceiling. The right pane of Figure 1 above illustrates the implications of this finding. In all three countries, the differences in engagement between respondents who were mobilized and were not mobilized is statistically significant. The index of political engagement predicted by Model 3 for a typical Italian respondent who was not mobilized is 1.9 , which increases to 2.4 for a comparable respondent who was mobilized. However, the increase in predicted engagement is slightly bigger among both British (from 1.5 to 2.1) and German (from 1.5 to 2.2) respondents. The differences 
between countries become clearer if we compare relative rather than absolute figures: the predicted engagement for mobilized respondents divided by that for non-mobilized respondents is 1.46 in Germany, 1.43 in Britain, but only 1.24 in Italy. In sum, online mobilization is associated with political engagement more strongly where overall levels of engagement are lower, as predicted by $\mathrm{H} 3 .^{9}$

Finally, H4 predicts that attentiveness to the campaign moderates the relationship between mobilization and engagement more strongly where overall levels of engagement are lower, i.e., among British and German respondents compared to Italian ones. To test this hypothesis, Model 4 in Table 2 includes three-way interaction terms between mobilization, attention, and country (again, with Italy as reference category). With this set-up, the results can be interpreted as follows: the coefficient for mobilization captures the relationship between mobilization and engagement only among Italian respondents who did not pay attention to the campaign; the two-way interactions between mobilization and Germany/UK capture the additional effects of mobilization among respondents who did not pay attention in those countries, in addition to those captured by the interaction-less mobilization coefficient; the two-way interaction between mobilization and attention captures the extent to which the relationship between mobilization and engagement changes at different levels of attention only among Italian respondents; finally, the three-way interactions between mobilization, attention, and Germany/UK capture the additional change in the relationship between mobilization and engagement at different levels of attention that can be observed among British and German respondents, on top of that observed among Italian respondents.

\footnotetext{
${ }^{9}$ A less stringent test of this hypothesis can be achieved by conducting separate regression analyses for each country rather than on a pooled dataset, and comparing the magnitude of the coefficients for digital mobilization in different countries. The results show that the coefficient for online mobilization is positive and significant in all three countries, but its magnitude is higher in the UK $(B=0.338, S D=0.038)$ and Germany $(B=0.323, S D=0.049)$ than Italy $(B=0.237, S D=0.032)$. The models are available in the Supplementary Material section for this article on the journal website. 
As can be seen from Model 4 in the last two columns of Table 2, when we consider country differences the relationship between mobilization and engagement is still positive, and the strength of this relationship decreases as attention increases in Germany and, especially, the UK, as the coefficients for the three-way interactions are negative and significant. However, this is not the case in Italy, as the coefficient for the two-way interaction is still negative as in Model 2, but no longer significant. As predicted by H4, the strength of the positive relationship between mobilization and engagement does not change as attention to the campaign increases where overall engagement was higher (Italy), but it decreases significantly as attention increases where overall engagement was lower (Germany and UK). ${ }^{10}$

\section{Figure 2 about here}

Effect size estimates, plotted in Figure 2, help assessing the implications of these findings. Across all countries and all levels of attention to the campaign, predicted engagement is substantially and significantly higher among respondents who were mobilized online than among those who were not. (The only exception is British respondents highly attentive to the campaign, among whom the predicted difference between those who were and were not mobilized falls just inside the 95\% confidence intervals.) However, in Italy the predicted increase in political engagement for respondents who were mobilized is very similar across low- and high-attention voters. Among respondents who were not mobilized online, the highly attentive are predicted to engage in 2.1 activities, the less attentive in 1.7 activities, while among those who were mobilized online, the models predict that the highly attentive

\footnotetext{
${ }^{10}$ Similar to H3, this hypothesis could also be tested by running separate analyses for each country. Results of such analyses confirm the hypothesis, as the coefficients for online mobilization are positive and significant in all three countries, but the coefficients for the interaction term between mobilization and attention, while being negative in all three countries, are significant only in Germany and the UK. This confirms that campaign attentiveness moderates the relationship between mobilization and engagement in Germany and the UK, but not in Italy, as predicted by H4. The models are available in the Supplementary Material section for this article on the journal website. 
engaged in 2.6 activities and the less attentive in 2.2 activities. These differences are essentially equal in size.

By contrast, in Germany and the UK the predicted gaps in engagement between highand low-attention respondents shrink substantially when mobilization also occurred. Model 4 predicts that, among respondents who were not mobilized online, those who were highly attentive engaged in twice as many activities than those who were less attentive than average (1.9 versus 0.8 in Britain and 1.8 versus 1.3 in Germany; both differences are statistically significant). By contrast, among respondents who were mobilized online, predicted engagement was essentially identical at high and low levels of attention (2.2 versus 2.1 in Germany and 2.2 for both groups in the UK; none of these differences are statistically significant). Being mobilized online is associated with a predicted increase in engagement that is identical among the more and the less attentive Italian voters ( 0.4 on a 0-6 scale), but in Germany the increase is double for the less attentive (0.8) than the more attentive (0.4), and in the UK it is four times as large (1.3 vs 0.3$)$.

Moreover, online mobilization seems to have contributed to levelling cross-country differences in political engagement among low-attention voters. British and German respondents who did not follow the campaign closely and were not mobilized online are predicted to engage in fewer activities than Italian ones ( 0.8 and 1.3 versus 1.7 ; all differences are statistically significant), but among low-attention respondents who were mobilized online predicted engagement increased to 2.2 in Italy and the UK and 2.1 in Germany, and none of these country differences are statistically significant. Thus, online mobilization may have potential to bridge participatory disparities rooted in different levels of campaign attentiveness both within and between countries.

A strong note of caution is in order with respect to the causal nature of the correlations presented here. As discussed earlier, the cross-sectional and observational nature of the data 
implies that endogeneity cannot be ruled out. Online mobilization may be positively associated with political engagement because mobilization spurs engagement, but it may also be that those who are already engaged are more likely to be mobilized online, or to recall being mobilized, or both. However, some of the mitigating factors discussed above should also be considered. On theoretical grounds, online mobilization can be expected to be less strategic than its offline counterpart, and so it should target a relatively broader set of individuals, including some who are less predisposed towards political action and on whom mobilization may have a larger marginal impact. Moreover, to the extent that some selection bias may have inflated the relationship between mobilization and engagement, campaign attentiveness should be expected to further enhance this bias, and so in theory the relationship between mobilization and engagement should have become stronger as attention increased at both individual and aggregate levels. This was the opposite to what H2, H3 and H4 predicted, and the fact that I still found support for these hypotheses suggests that the validity of these findings, while limited by the nature of the data and in need of closer scrutiny based on experimental designs, should not be ruled out. Finally, PSM allowed calibrating the multivariate analyses so that the selection biases that could cause endogeneity are accounted for as rigorously as possible within the limits of observational data, and controlling for variables known to cause over-reporting of exposure to information and political engagement should reduce the risk of spurious results.

That being said, experimental research is urgently needed to confirm the causal nature of the correlations reported here. Unfortunately, such research has hitherto focused on the relationship between mobilization and voter turnout, as opposed to broader repertoires of political engagement, and has addressed direct rather than differential effects-thus overlooking important implications of mobilization on political equality, as shown by Enos, Fowler, and Vavreck (2014). More work is also needed to disentangle what types of online 
mobilization -in terms of sources, timing, content, and technology used-may play the strongest role, and what types of participatory behaviours are more likely to be affected by them. The findings of this study thus raise important new challenges for experimental research on digital mobilization.

\section{Conclusions}

This study has shown that digital mobilization is a relevant piece of the puzzle of political engagement, which in turn is an indispensable component of democratic governance. The findings reported here represent four important contributions to existing knowledge of the political implications of online mobilization: first, that the effects of online mobilization on broader patterns of political engagement may be even stronger than the effects on turnout; secondly, that these effects are differential rather than uniform across different types of voters, and should thus be studied as such; thirdly, that contrary to pessimistic views of digital media as reinforcing political inequalities, online mobilization may reduce participatory disparities; fourthly, that both direct and differential effects vary as a function of context, and in particular of the overall levels of engagement observed in a political system at a given point in time.

These findings have particularly important implications for political equality, a crucial aspect of democratic quality. At least in the second-order elections studied here, the increases in political engagement that may result from online mobilization seem to be concentrated among the less attentive segments of the public. This suggests that digital mobilization may foster greater political equality by disproportionately engaging relatively marginal citizens. This conclusion is in contrast with studies of offline mobilization, a difference that I have argued may be explained by the fact that online mobilization reaches broader audiences due to its lower costs and greater social embeddedness. It also contradicts the first generation of 
research on the internet and politics, which argued that the web would simply reinforce engagement among those who were already involved (see e.g. Norris, 2003). Since then, digital media has evolved to allow frequent, informal everyday contacts among individuals, some of which involve politics and may attract less attentive voters, who may be relatively more open to social influence precisely because they are less involved.

However, online mobilization does not happen in a vacuum. All else being equal, the more engaged the citizenry is at a given place and time, the more difficult it is that online mobilization will be associated with substantial participatory boosts. Conversely, the less engaged a population happens to be, the bigger the difference that online mobilization may make. These findings suggest optimism on the levelling role of online mobilization, which may contribute to citizens' engagement when and where such engagement is especially lacking and thus, arguably, most needed. However, the other side of the coin is that online mobilization may matter less when and where participation matters more-in high-stakes contexts where overall engagement is higher and greater efforts are needed to eradicate participatory gaps. Accordingly, the second-order elections studied here provide a less compelling test of the role of online mobilization than general elections would. Comparative research featuring a broader set of countries, ideally including general elections and spanning across different electoral and non-electoral periods, is needed to disentangle these puzzles.

To the extent that a more engaged citizenry is a crucial component of democratic governance, this study suggests that digital mobilization, far from being just an appendix of parties' electioneering and citizens' repertoires of political action, may play an independent, positive role in contemporary Western polities. The internet now provides many convenient avenues for citizens to mobilize and be mobilized by others in a way that is more informal, more continuous, and more closely connected with individuals' everyday lives than (still highly relevant) face-to-face mobilization. Two decades after Voice and Equality was 
published, one of the main reasons why citizens participate in politics is still that someone asked them to, and inequalities in who gets asked and who does not are still reflected in who participates and whose demands are communicated to elites. However, this study has shown that digital media are promoting new and potentially more inclusive practices of political mobilization, with potentially momentous, but context-conditional, implications for both levels of and inequalities in political engagement. 


\section{References}

AAPOR [American Association for Public Opinion Research] (2011) Standard Definitions: Final Dispositions of Case Codes and Outcome Rates for Surveys. 7th edition.

Aldrich, J. H., Gibson, R. K., Cantijoch, M., \& Konitzer, T. (2016). Getting out the vote in the social media era: Are digital tools changing the extent, nature and impact of party contacting in elections? Party Politics, 22(2), 165-178.

Baker, R., Blumberg, S. J., Brick, J. M., Couper, M. P., Courtright, M., Dennis, J. M., ... \& Zahs, D. (2010). Research synthesis AAPOR report on online panels. Public Opinion Quarterly, 74(4), 711-781.

Bond, R. M., Fariss, C. J., Jones, J. J., Kramer, A. D., Marlow, C., Settle, J. E., \& Fowler, J. H. (2012). A 61-million-person experiment in social influence and political mobilization. Nature, 489(7415), 295-298.

Boulianne, S. (2009). Does Internet use affect engagement? A meta-analysis of research. Political communication, 26(2), 193-211.

Boulianne, S. (2015). Social Media Use and Participation: a Meta-analysis of Current Research. Information, Communication \& Society, 18(5), 524-538.

Cantijoch, M., Cutts, D., \& Gibson, R. (2015). Moving Slowly up the Ladder of Political Engagement: A 'Spill-Over' Model of Internet Participation. The British Journal of Politics and International Relations, 18(1), 26-48.

Enos, R. D., Fowler, A., \& Vavreck, L. (2014). Increasing inequality: the effect of GOTV mobilization on the composition of the electorate. The Journal of Politics, 76(01), 273-288.

Gibson, R., \& Cantijoch, M. (2013). Conceptualizing and measuring participation in the age of the internet: Is online political engagement really different to offline? The Journal of Politics, 75(03), 701-716. 
Gil de Zúñiga, H., Molyneux, L., \& Zheng, P. (2014). Social Media, Political Expression, and Political Participation: Panel Analysis of Lagged and Concurrent Relationships. Journal of Communication, doi:10.1111/jcom.12103

Green, D.P., \& Gerber, A.S. (2004). Get Out the Vote! How to Increase Voter Turnout. Washington, DC: Brookings Institution Press.

Hassell, H. J., \& Monson, J. Q. (2014). Campaign Targets and Messages in Direct Mail Fundraising. Political Behavior, 36(2), 359-376.

Heerwegh, D. (2009). Mode differences between face-to-face and web surveys: an experimental investigation of data quality and social desirability effects. International Journal of Public Opinion Research, 21(1), 111-121.

Huckfeldt, R., \& Sprague, J. (1992). Political Parties and Electoral Mobilization: Political Structure, Social Structure, and the Party Canvass. American Political Science Review, 86(01), 70-86.

Karp, J. A., \& Banducci, S. A. (2007). Party mobilization and political participation in new and old democracies. Party Politics, 13(2), 217-234.

Klofstad, C. A., Sokhey, A. E., \& McClurg, S. D. (2013). Disagreeing about disagreement: How conflict in social networks affects political behaviour. American Journal of Political Science, 57(1), 120-134.

Kreuter, F., Presser, S., \& Tourangeau, R. (2008). Social desirability bias in CATI, IVR, and Web surveys the effects of mode and question sensitivity. Public Opinion Quarterly, 72(5), 847-865.

Krueger, B.S. (2006). A Comparison of Conventional and Internet Political Mobilization. American Politics Research, 34(6), 759-776.

Malhotra, N., Michelson, M.R., \& Valenzuela, A.A. (2012). Emails from Official Sources Can Increase Turnout. Quarterly Journal of Political Science, 7(3), 321-332. 
Nickerson, D.W. (2007). Does Email Boost Turnout? Quarterly Journal of Political Science, 2(4), 369-379.

Nielsen, R. K. (2011). Mundane internet tools, mobilizing practices, and the coproduction of citizenship in political campaigns. New Media \& Society,13(5), 755-771.

Norris, P. (2003). Preaching to the converted? Pluralism, participation and party websites. Party politics, 9(1), 21-45.

Oser, J., Hooghe, M., and Marien, S. (2013). Is online participation distinct from offline participation? A latent class analysis of participation types and their stratification. Political Research Quarterly 66 (1): 91-101.

Pasek, J. (2015). When will Nonprobability Surveys Mirror Probability Surveys? Considering Types of Inference and Weighting Strategies as Criteria for Correspondence. International Journal of Public Opinion Research, doi:10.1093/ijpor/edv016

Rosenstone, S., \& Hansen, J. M. (1993). Mobilization, participation and democracy in America. New York: Longman.

Sanders, D., Clarke, H. D., Stewart, M. C., \& Whiteley, P. (2007). Does mode matter for modeling political choice? Evidence from the 2005 British Election Study. Political Analysis, 15(3), 257-285.

Vaccari, C. (2013). Digital politics in Western democracies: a comparative study. Baltimore: Johns Hopkins University Press.

Vavreck, L. (2007). The exaggerated effects of advertising on turnout: The dangers of self-reports. Quarterly Journal of Political Science, 2(4), 325-343.

Verba, S., Schlozman, K. L., Brady, H. E., \& Brady, H. E. (1996). Voice and equality: Civic voluntarism in American politics. Cambridge, MA: Harvard University Press.

Wielhouwer, P. W., \& Lockerbie, B. (1994). Party contacting and political participation, 1952-90. American Journal of Political Science, 211-229. 
Table 1 - Frequency of Variables Comprising the Index of Political Engagement, by

\section{Country}

\begin{tabular}{lrrr}
\hline & Germany & Italy & UK \\
\hline Tried to convince someone to vote for a party, leader, or candidate & $37.4 \%$ & $50.2 \%$ & $38.3 \%$ \\
Participated in the activities of a political party & $16.8 \%$ & $17.9 \%$ & $14.6 \%$ \\
Took part in public meetings and rallies on the elections & $26.7 \%$ & $42.0 \%$ & $17.2 \%$ \\
Signed a petition or subscribed a referendum & $41.7 \%$ & $51.6 \%$ & $36.7 \%$ \\
Contacted a politician to support a cause & $15.0 \%$ & $18.3 \%$ & $29.4 \%$ \\
Discussed national politics on social media & $49.8 \%$ & $55.8 \%$ & $52.3 \%$ \\
$N$ & 708 & 1196 & 1091 \\
\hline
\end{tabular}

Note. The first five items were introduced by the question: "People often carry out various activities in order to participate in politics. During the last 12 months, have you taken part in any of the activities listed below? Yes; No; Don't remember". The sixth item was introduced by the question: "Various political activities are carried out on social networks / social media platforms such as Facebook, Twitter, YouTube, etc. During the past 12 months have you discussed national politics on social media? Yes; No; Don't remember". 
Table 2 - Dependent Variable: Political Engagement (0-6 Index)

\begin{tabular}{|c|c|c|c|c|c|c|c|c|}
\hline & \multicolumn{2}{|c|}{ Model 1} & \multicolumn{2}{|c|}{ Model 2} & \multicolumn{2}{|c|}{ Model 3} & \multicolumn{2}{|c|}{ Model 4} \\
\hline & B & s.e. & B & s.e. & B & s.e. & B & s.e. \\
\hline Mobilized online & $0.299^{* * *}$ & 0.021 & $0.702^{* * *}$ & 0.080 & $0.216^{* * *}$ & 0.031 & $0.245^{*}$ & 0.109 \\
\hline Mobilized*United Kingdom & & & & & $0.141^{* * *}$ & 0.048 & $1.512^{* * *}$ & 0.213 \\
\hline Mobilized*Germany & & & & & $0.161^{* * *}$ & 0.054 & $0.474^{* * *}$ & 0.180 \\
\hline Attention to the campaign & $0.489 * * *$ & 0.056 & $0.685^{* * *}$ & 0.067 & $0.479 * * *$ & 0.056 & $0.361^{* * *}$ & 0.083 \\
\hline Attention*United Kingdom & & & & & & & $1.269^{* * *}$ & 0.168 \\
\hline Attention*Germany & & & & & & & 0.219 & 0.139 \\
\hline Mobilized*attention & & & $-0.509 * * *$ & 0.094 & & & -0.042 & 0.129 \\
\hline Mobilized*attention*United Kingdom & & & & & & & $-1.591^{* * *}$ & 0.242 \\
\hline Mobilized*attention*Germany & & & & & & & $-0.430 *$ & 0.219 \\
\hline United Kingdom & $-0.222^{* * *}$ & 0.024 & $-0.218^{* * *}$ & 0.024 & $-0.273^{* * *}$ & 0.028 & $-1.370^{* * *}$ & 0.155 \\
\hline Germany & $-0.183^{* * *}$ & 0.029 & $-0.173^{* * *}$ & 0.029 & $-0.245^{* * *}$ & 0.037 & $-0.403^{* * *}$ & 0.114 \\
\hline Ratio of political messages on social media & $0.742^{* * *}$ & 0.046 & $0.738^{* * *}$ & 0.045 & $0.728^{* * *}$ & 0.046 & $0.743^{* * *}$ & 0.046 \\
\hline Visited party websites & $0.446^{* * *}$ & 0.026 & $0.452^{* * *}$ & 0.026 & $0.437^{* * *}$ & 0.026 & $0.460 * * *$ & 0.025 \\
\hline Interest in politics & $0.259^{* * *}$ & 0.050 & $0.268^{* * *}$ & 0.050 & $0.268^{* * *}$ & 0.050 & $0.277^{* * *}$ & 0.050 \\
\hline Trust in political parties & 0.044 & 0.029 & 0.054 & 0.030 & 0.038 & 0.030 & $0.071^{*}$ & 0.031 \\
\hline Political efficacy & $0.525^{* * *}$ & 0.055 & $0.524^{* * *}$ & 0.055 & $0.532^{* * *}$ & 0.054 & $0.505^{* * *}$ & 0.055 \\
\hline Ideology: right & $0.100^{* * *}$ & 0.029 & $0.102^{* * *}$ & 0.029 & $0.106^{* * *}$ & 0.029 & $0.095^{* * *}$ & 0.029 \\
\hline Ideology: centre & $0.260^{* * *}$ & 0.036 & $0.258^{* * *}$ & 0.035 & $0.262^{* * *}$ & 0.036 & $0.243^{* * *}$ & 0.036 \\
\hline Ideology: left & $0.118^{* * *}$ & 0.027 & $0.113^{* * *}$ & 0.027 & $0.120^{* * *}$ & 0.027 & $0.097^{* * *}$ & 0.027 \\
\hline Frequency of sc & $0.188^{* * *}$ & 0.058 & $0.164^{* * *}$ & 0.058 & $0.183^{* * *}$ & 0.058 & $0.173^{* * *}$ & 0.058 \\
\hline Political information: social media & $0.258^{* * *}$ & 0.061 & $0.264^{* * *}$ & 0.061 & $0.269^{* * *}$ & 0.061 & $0.256^{* * *}$ & 0.061 \\
\hline Political information: websites & $0.254^{* * *}$ & 0.071 & $0.250 * * *$ & 0.071 & $0.243^{* * *}$ & 0.071 & $0.252^{* * *}$ & 0.071 \\
\hline Political information: newspapers & -0.018 & 0.039 & -0.010 & 0.040 & -0.002 & 0.040 & -0.015 & 0.040 \\
\hline Political information: radio & $0.072^{*}$ & 0.037 & $0.071^{*}$ & 0.036 & 0.066 & 0.037 & 0.048 & 0.035 \\
\hline Political information: television & -0.043 & 0.046 & -0.028 & 0.046 & -0.042 & 0.046 & -0.059 & 0.045 \\
\hline Gender (male) & $-0.083^{* * *}$ & 0.019 & $-0.081^{* * *}$ & 0.019 & $-0.084^{* * *}$ & 0.019 & $-0.079 * * *$ & 0.019 \\
\hline Age & -0.064 & 0.045 & $-0.091^{*}$ & 0.046 & -0.065 & 0.045 & $-0.116^{*}$ & 0.047 \\
\hline Education & $-0.117^{* * *}$ & 0.030 & $-0.123^{* * *}$ & 0.030 & $-0.107^{* * *}$ & 0.030 & $-0.118^{* * *}$ & 0.030 \\
\hline Income & $-0.125^{* * *}$ & 0.035 & $-0.140 * * *$ & 0.035 & $-0.125^{* * *}$ & 0.035 & $-0.139 * * *$ & 0.035 \\
\hline Intercept & $-1.226^{* * *}$ & 0.066 & $-1.381^{* * *}$ & 0.073 & $-1.196^{* * *}$ & 0.067 & $-1.047^{* * *}$ & 0.080 \\
\hline Pearson's Chi square & 4373.630 & & 4361.211 & & 4365.94 & & 4370.497 & \\
\hline Chi square/degrees of freedom & 0.918 & & 0.916 & & 0.917 & & 0.919 & \\
\hline Log-likelihood & -7608.541 & & -7592.852 & & -7603.024 & & -7547.639 & \\
\hline Likelihood ratio Chi square & $2801.622^{* * *}$ & & $2833.000^{* * *}$ & & $2812.656^{* * *}$ & & $2923.427^{* * *}$ & \\
\hline
\end{tabular}

Note. $N=2679$ for all models. Cell entries are unstandardized coefficients for Poisson regressions. ${ }^{* * *} \mathrm{p} \leq 0.001{ }^{* *} \mathrm{p} \leq 0.01{ }^{*} \mathrm{p} \leq 0.05$ 
Figure 1 - Effect Size Estimates of Political Engagement from Models 2 and 3, with 95\%

\section{Confidence Intervals}

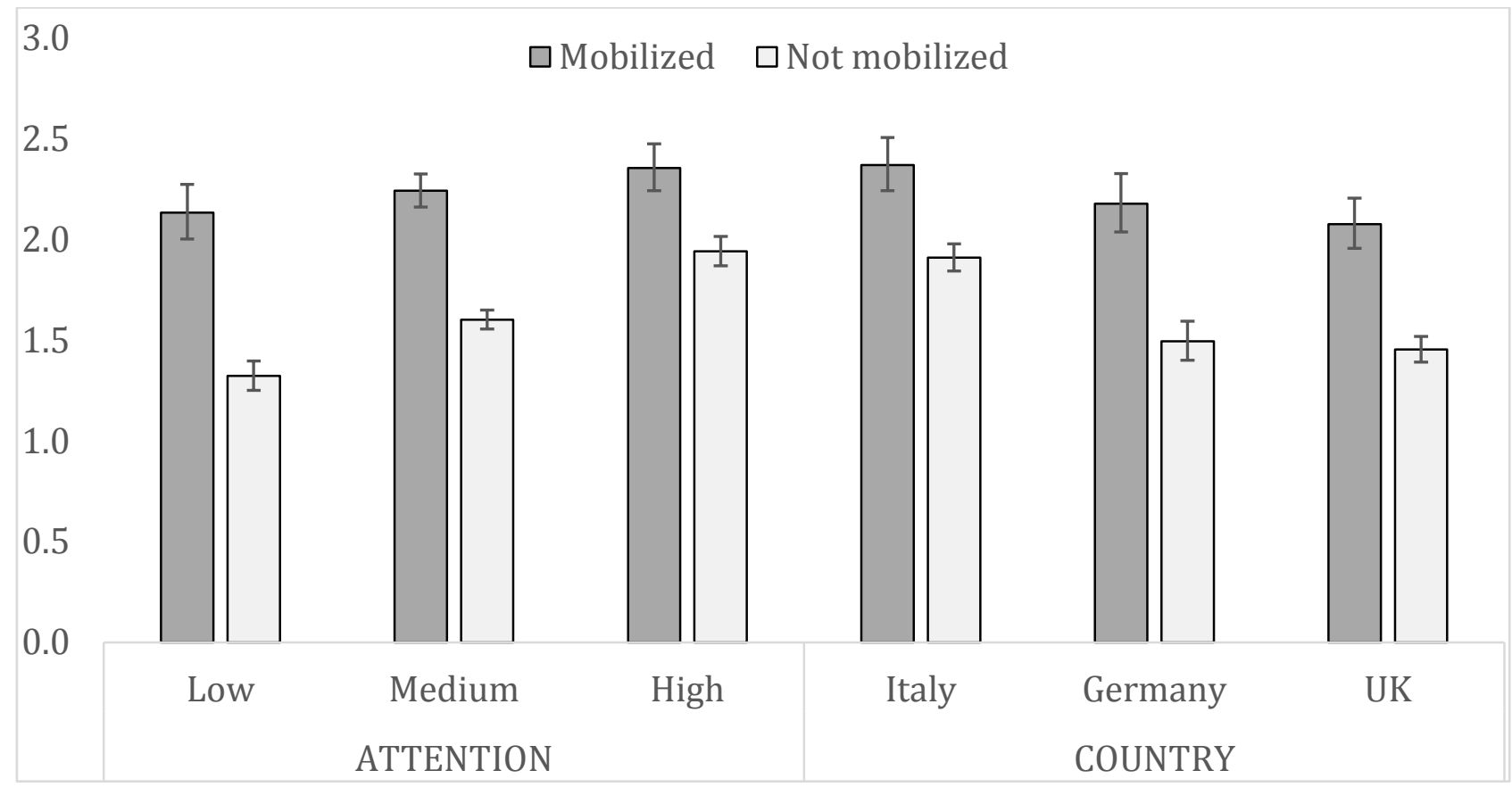

Note: the values are calculated on the basis of Model 2 (for attention) and Model 3 (for country) in Table 2. The estimates are based on the means across the pooled sample for all variables apart from mobilization, attention, and country. The values for Mobilization are 0 (not mobilized) and 1 (mobilized). The values for Attention are one standard deviation below the mean (low attention), the mean (medium attention), and one standard deviation above the mean (high attention). The values for Country are 1 when the effect size is calculated for the country in question and 0 when it is not. 
Figure 2 - Effect Size Estimates of Political Engagement from Model 4, with 95\%

\section{Confidence Intervals}

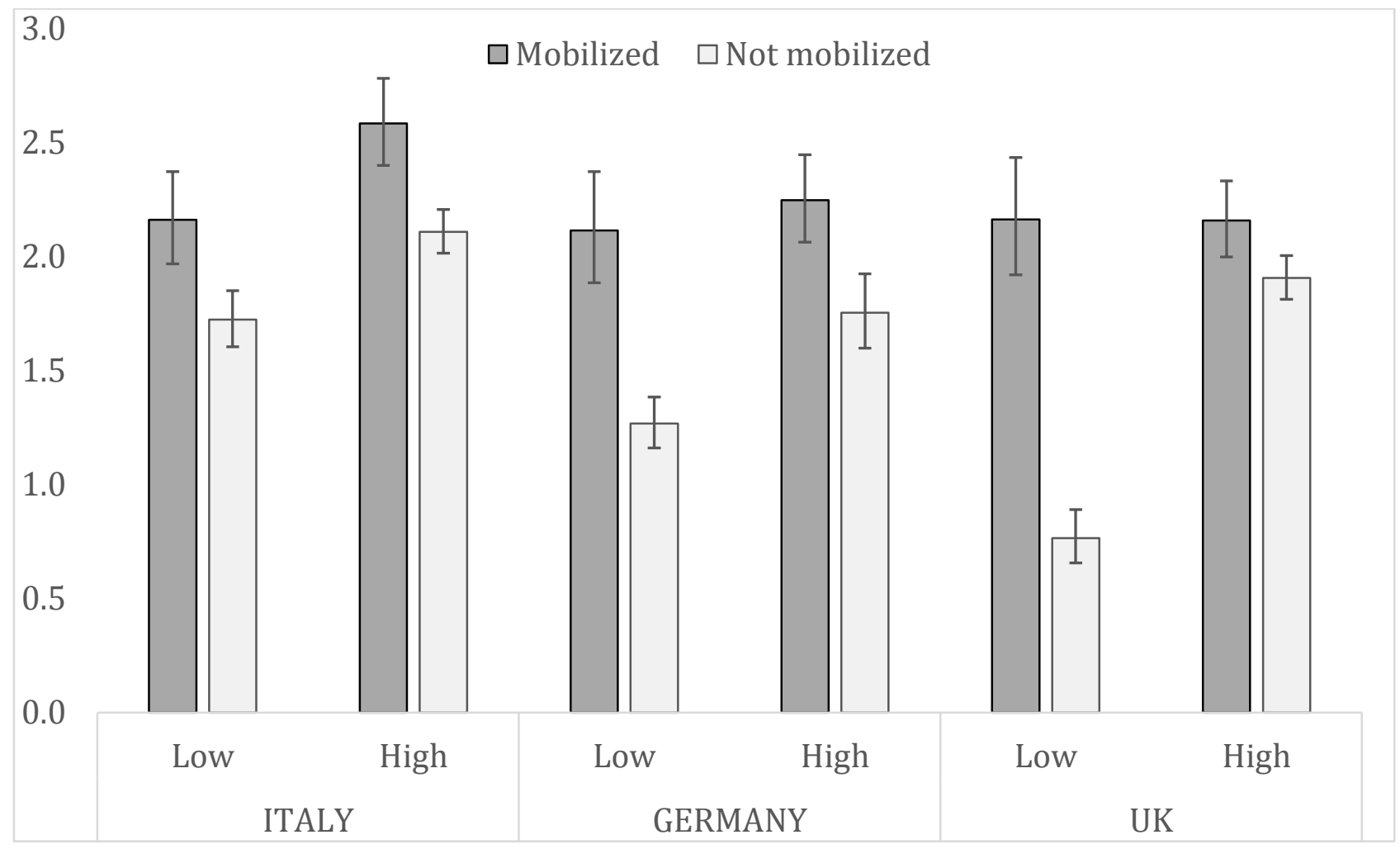

Note: the values are calculated on the basis of Model 4 in Table 2. The estimates are based on the means across the pooled sample for all variables apart from mobilization and attention. The values for Mobilization are 0 (not mobilized) and 1 (mobilized). The values for Attention are one standard deviation below the mean (low attention) and one standard deviation above the mean (high attention). 